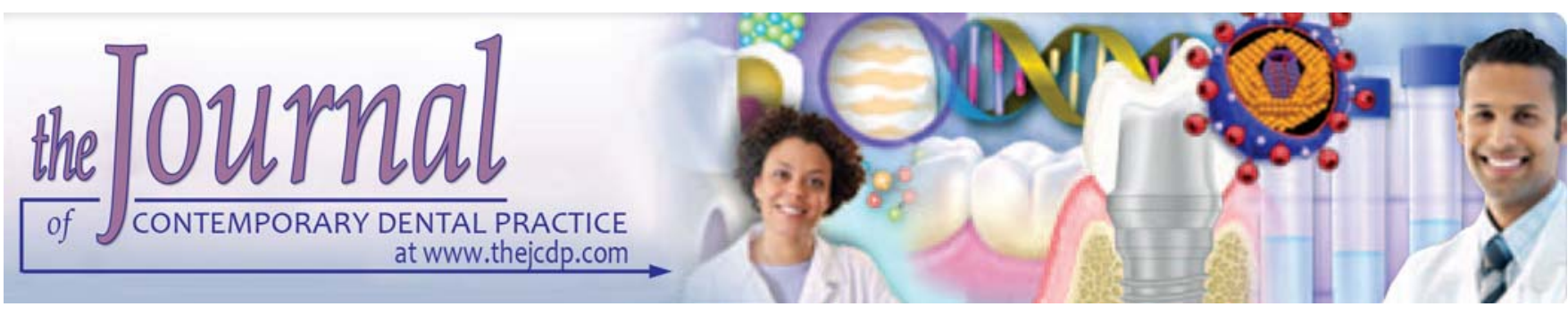

\title{
Evaluation of Periodontal Status in Alcoholic Liver Cirrhosis Patients: A Comparative Study
}

\author{
K Vijay Raghava, H Shivananda, Darshan Mundinamane, Vinita Boloor, Biju Thomas
}

\begin{abstract}
Aim: Bacterial infections are common complicating findings in course of liver cirrhosis, most of them being Gram-negative. Similarly periodontal pathogens are also mostly $\mathrm{Gram}$-negative bacteria hence the objective was to evaluate the periodontal status in alcoholic liver cirrhosis patients and to compare the periodontal status of alcoholic liver cirrhosis patients in:

a. Smokers with periodontitis and

b. Nonsmokers with periodontitis.
\end{abstract}

Materials and methods: A total of 150 patients made up the sample of this study. The sample size was divided into four groups. The first two groups comprised of 50 patients each comprising of patients with periodontitis who were nonsmokers and patients with periodontitis who were smokers respectively and the next two groups comprised of 25 patients each, which included patients diagnosed as suffering from alcoholic liver cirrhosis who are nonsmokers and patients diagnosed as suffering from alcoholic liver cirrhosis who are smokers.

Screening examination included a proper medical history, dental history and Russell's periodontal index was done to evaluate and compare the periodontal status among the selected groups.

Results: The data obtained was subjected to statistical analysis using the ANOVA Fisher's F-test. Multiple group comparisons were made using the Tukey's HSD test.

Conclusion: Conclusions that can be drawn from this study are:

1. Alcoholic liver cirrhosis patients demonstrated greater alveolar bone loss and increased periodontal destruction.

2. There is very high statistically significant difference on periodontal destruction in alcoholic liver cirrhosis patients (with or without smokers) when compared to the control group.

Clinical significance: Periodontal diseases are bacterial infections associated with a bacterial load or insult to the host that elicits a strong inflammatory response cumulating to produce significant pathologic alterations in the systemic status of the host. Alcoholic liver cirrhosis patients as a consequence of liver dysfunction have elevated levels of serum cytokines. These are involved in the destructive process of periodontal disease probably through enhancement of collagenase and metalloproteinase activity. Hence, a study has been planned to evaluate periodontal status in patients with alcoholic liver cirrhosis.
Keywords: Liver cirrhosis, Periodontal diseases, Pathogens, Smokers.

How to cite this article: Raghava KV, Shivananda $H$, Mundinamane D, Boloor V, Thomas B. Evaluation of Periodontal Status in Alcoholic Liver Cirrhosis Patients: A Comparative Study. J Contemp Dent Pract 2013;14(2):179-182.

\section{Source of support: Nil}

Conflict of interest: None declared

\section{INTRODUCTION}

Periodontal diseases are bacterial infections associated with a bacterial load or insult to the host that elicits a strong inflammatory response cumulating to produce significant pathologic alterations in the systemic status of the host.

Cirrhosis is characterized anatomically by widespread nodules in the liver combined with fibrosis. A lcohol abuse is a leading cause of morbidity and mortality throughout the world. It is estimated that as many as $10 \%$ of men and $3 \%$ of women may suffer from persistent problems related to the use of alcohol. ${ }^{1}$

Alcoholic liver cirrhosis patients as a consequence of liver dysfunction have elevated levels of serum cytokines. These are involved in the destructive process of periodontal disease probably through enhancement of collagenase and metalloproteinase activity. So greater periodontal breakdown may be associated with altered immune response and increased cytokine levels. ${ }^{2,3}$

Hence, a study has been planned to evaluate periodontal status in patients with alcoholic liver cirrhosis.

\section{MATERIALS AND METHODS}

\section{Sample Size}

A total of 150 patients made up the sample of this study. The sample size was divided into four groups. The first two groups comprised of 50 patients each and the next two groups comprised of 25 patients each. 


\section{Study Design}

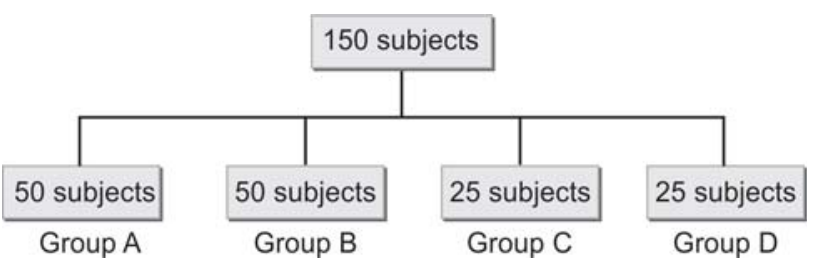

- GroupA: Patients with periodontitis (nonsmokers, nonalcoholic and not suffering from any systemic disease).

- Group B: Patients with periodontitis (smokers, nonalcoholic and not suffering from any systemic disease).

- Group C: Patients diagnosed as suffering from al coholic liver cirrhosis who are nonsmokers.

- Group D: Patients diagnosed as suffering from al coholic liver cirrhosis who are smokers.

\section{Screening Examination includes}

- Medical history

- Dental history

- Russell's periodontal index: Its done to evaluate and compare the periodontal status among the selected groups.

\section{Inclusion Criteria}

- Patients with pockets more than $4 \mathrm{~mm}$ or attachment loss of $1.5 \mathrm{~mm}$ or more from cementoenamel junction.

- Patients should not have undergone oral prophylaxis at least 6 months prior to this examination.

- Patients having not less than 12 natural teeth are selected for examination.

- Subjects to be included in group B should be smoking 3 to 5 cigarettes/day for duration of 4 to 5 years.

\section{Exclusion Criteria}

- Patients with nonalcoholic cirrhosis.

- Patients with other systemic diseases which has influence on periodontal tissues.

- Pregnant women.

- Patients under antibiotic therapy with in last 6 months.

\section{STATISTICAL ANALYSIS}

The data obtained was subjected to statistical analysis using the A N OV A (analysis of variance) Fisher's F-test. M ultiple group comparisons were made using the Tukey's HSD test. ${ }^{4}$

The values obtained were subjected to statistical analysis. The means of Russell's periodontal index of the four groups were statistically analyzed using A NOVA.

Table 1 shows the comparison of mean of Russell's periodontal index scores among the groups A, B, C and D.

The mean value of control group is 1.6657 .

The mean value of smokers group is 2.1029.

The mean value of alcoholic cirrhosis without smokers is 3.7063 .

The mean value of alcoholic cirrhosis with smokers is 4.7416.

The $p$-value is 0.001 . The difference observed was statistically very highly significant.

Table 2 shows multiple comparison of mean difference of Russell's periodontal index scores between the groups.

The difference in mean index scores of the control group was highly significant $(p=0.002)$ when compared to smokers group.

The difference in mean index scores of the control group was very highly significant $(p=0.001)$ when compared to al coholic cirrhosis without smokers and al coholic cirrhosis with smokers.

\begin{tabular}{|c|c|c|c|c|c|c|c|}
\hline & \multirow[t]{2}{*}{$\mathrm{N}$} & \multirow[t]{2}{*}{ Mean } & \multirow{2}{*}{$\begin{array}{c}\text { Std. } \\
\text { deviation }\end{array}$} & \multicolumn{2}{|c|}{ Confidence interval \% } & \multirow[t]{2}{*}{$\mathrm{F}$} & \multirow[t]{2}{*}{$p$-value } \\
\hline & & & & $\begin{array}{l}\text { Lower } \\
\text { bound }\end{array}$ & $\begin{array}{l}\text { Upper } \\
\text { bound }\end{array}$ & & \\
\hline Control & 50 & 1.6657 & 0.34954 & 1.5664 & 1.7651 & & \\
\hline Smokers & 50 & 2.1029 & 0.33706 & 2.0071 & 2.1987 & & \\
\hline Alcoholic liver cirrhosis without smokers & 25 & 3.7063 & 1.14274 & 3.2346 & 4.1780 & & \\
\hline Alcoholic liver cirrhosis with smokers & 25 & 4.7416 & 0.56435 & 4.5086 & 4.9745 & 193.21 & 0.001 VHS \\
\hline
\end{tabular}

VHS: Very highly significant

Table 2: Multiple comparison of mean difference of index scores between the groups (Department variable index Score-Tukey HSD)

\begin{tabular}{|c|c|c|c|}
\hline Group (I) & Group (J) & $\begin{array}{l}\text { Mean difference } \\
(\mathrm{I}-\mathrm{J})\end{array}$ & p-value \\
\hline \multirow[t]{3}{*}{ Control } & Smokers & -0.4372 & $0.002 \mathrm{HS}$ \\
\hline & Alcoholic liver cirrhosis without smokers & -2.0406 & 0.001 VHS \\
\hline & Alcoholic liver cirrhosis with smokers & -3.0758 & 0.001 VHS \\
\hline \multirow[t]{2}{*}{ Smokers } & Alcoholic liver cirrhosis without smokers & -1.6034 & $0.001 \mathrm{VHS}$ \\
\hline & Alcoholic liver cirrhosis with smokers & -2.6386 & 0.001 VHS \\
\hline Alcoholic liver cirrhosis without smokers & Alcoholic liver cirrhosis with smokers & -1.0352 & $0.001 \mathrm{VHS}$ \\
\hline
\end{tabular}

HS : Highly significant; VHS: Very highly significant 
Evaluation of Periodontal Status in Alcoholic Liver Cirrhosis Patients: A Comparative Study

\begin{tabular}{|c|c|c|c|c|c|c|c|}
\hline & & & \multicolumn{4}{|c|}{ Group } & \multirow[t]{2}{*}{ Total } \\
\hline & & & Control & Smokers & $\begin{array}{l}\text { Alcoholic liver } \\
\text { cirrhosis without } \\
\text { smokers }\end{array}$ & $\begin{array}{l}\text { Alcoholic liver } \\
\text { cirrhosis with } \\
\text { smokers }\end{array}$ & \\
\hline \multirow[t]{3}{*}{ INDSCR } & $1-2$ & $\begin{array}{c}\text { Count } \\
\%\end{array}$ & $\begin{array}{c}39 \\
78.0 \%\end{array}$ & $\begin{array}{c}25 \\
50.0 \%\end{array}$ & $\begin{array}{c}0 \\
0 \%\end{array}$ & $\begin{array}{c}0 \\
0 \%\end{array}$ & $\begin{array}{c}64 \\
42.7 \%\end{array}$ \\
\hline & $2-4.9$ & $\begin{array}{c}\text { Count } \\
\%\end{array}$ & $\begin{array}{c}11 \\
22.0 \%\end{array}$ & $\begin{array}{c}25 \\
50.0 \%\end{array}$ & $\begin{array}{c}19 \\
76.0 \%\end{array}$ & $\begin{array}{c}14 \\
56.0 \%\end{array}$ & $\begin{array}{c}69 \\
46.0 \%\end{array}$ \\
\hline & $5-8$ & $\begin{array}{c}\text { Count } \\
\%\end{array}$ & $\begin{array}{c}0 \\
0 \%\end{array}$ & $\begin{array}{c}0 \\
0 \%\end{array}$ & $\begin{array}{c}6 \\
24.0 \%\end{array}$ & $\begin{array}{c}11 \\
44.0 \%\end{array}$ & $\begin{array}{c}17 \\
11.3 \%\end{array}$ \\
\hline Total & & $\begin{array}{c}\text { Count } \\
\%\end{array}$ & $\begin{array}{c}50 \\
100 \%\end{array}$ & $\begin{array}{c}50 \\
100 \%\end{array}$ & $\begin{array}{c}25 \\
100 \%\end{array}$ & $\begin{array}{c}25 \\
100 \%\end{array}$ & $\begin{array}{c}150 \\
100 \%\end{array}$ \\
\hline
\end{tabular}

Table 3 shows the highest number of patients who had terminal periodontal disease. Scoring 5 to 8 belonged to alcoholic cirrhosis with smoker's category (44\%).

Highest number of patients who had simple gingivitis (scoring 1-2) belonged to the control group (78\%).

\section{DISCUSSION}

Alcohol may affect periodontal tissues through different mechanisms. There is evidence that al cohol has an adverse effect on host defense. It is associated with complement deficiency, defective neutrophil function (decreased adherence, motility, phagocytic activity) and increased frequency of infections. 5,6

The periodontium has been described as a potential reservoir of endotoxins, cytokines and lipid mediators produced elsewhere in the body. Exaggerated gingival inflammation, bluish-red discoloration and bleeding with slightest provocation are commonly seen in alcoholics. Alcohol may interfere with protein metabolism and tissue healing. Invitrostudies suggest that ethanol stimulates bone resorption and blocks the stimulation of bone formation. Finally, alcohol may have direct toxic effects on periodontal tissues. ${ }^{7}$

In our present study comparison (Table 1; G raph 1) of mean of R ussell's periodontal index scores among the four groups (control group, smokers, alcoholic cirrhosis without smokers and alcoholic cirrhosis with smokers) were done and results show ed that the $p$-value is $(0.001)$ the difference observed was statistically very highly significant. This is in accordance with the study conducted by Orit 0 ettingerBarak et al who found that liver cirrhosis demonstrated greater bone loss compared to healthy control. ${ }^{8}$

Orit 0 ettinger- $B$ arak et al also compared the panoramic radiographs between the control group and liver cirrhosis patients and found that the cirrhotic patients exhibited significantly greater alveolar bone loss when compared to control groups. ${ }^{9}$

In a study by Movin et al it was found that patients suffering from cirrhosis for more than 3 years showed

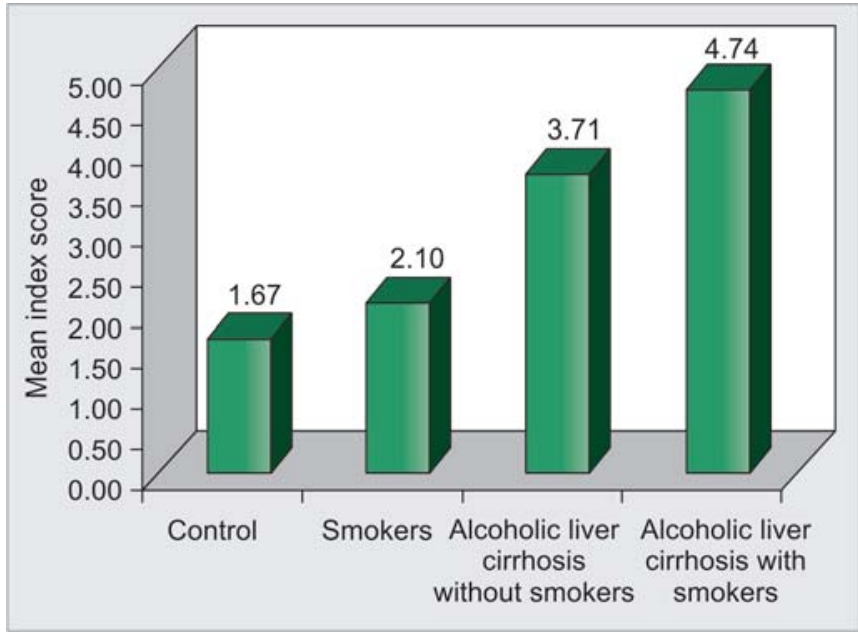

Graph 1: Comparison of mean scores of Russell's periodontal index between the groups

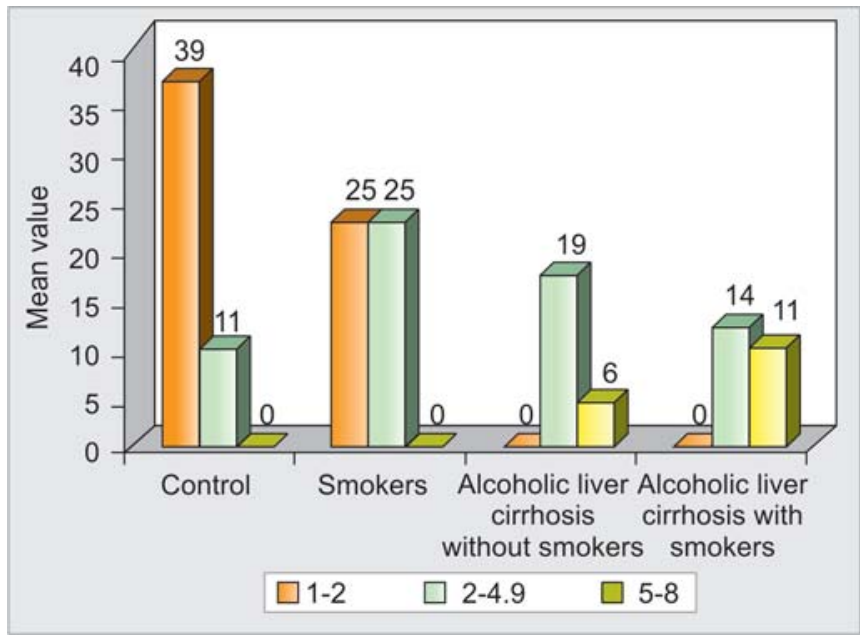

1-2: Simple gingivitis; 2-4.9: Established destructive periodontitis; 5-8: Terminal disease

Graph 2: Multiple comparison of Russell's periodontal index score

significantly greater loss of attachment, as well as more plaque and calculus compared with those with disease duration of less than 3 years. Our present study met the above criteria as most of the patients were diagnosed as having alcoholic liver cirrhosis for a period of more than 3 to 5 years. ${ }^{10}$ 
The results of this study are in agreement with studies conducted from cross-sectional and case-control studies in various populations which demonstrated that adult smokers are approximately three times more likely to have periodontitis when compared to nonsmokers. Tobaccoinduced alterations in microbial and host factors contribute to these del eterious effects of smoking on the periodontium. In longitudinal studies, the rate of periodontal disease progression is increased in smokers. ${ }^{11}$

Results of our present study also show that the (Table 3; Graph 3) highest number of patients who had terminal periodontal disease (scoring 5-8) belonged to alcoholic cirrhosis with smokers category (44\%). Highest number of patients who had simple gingivitis (scoring 1-2) belonged to the control group (78\%).

\section{CONCLUSION}

Conclusions that can be drawn from this study are as follows:

1. Alcoholic liver cirrhosis patients demonstrated greater alveolar bone loss and increased periodontal destruction.

2. There is very high statistically significant difference on periodontal destruction in alcoholic liver cirrhosis patients (with or without smokers) when compared to the control group.

3. Highest number of patients who had terminal periodontal disease (scoring 5-8) belonged to al coholic cirrhosis with smoker's category (44\%).

\section{CLINICAL SIGNIFICANCE}

A Icoholic liver cirrhosis patients as a consequence of liver dysfunction have elevated levels of serum cytokines. These are involved in the destructive process of periodontal disease probably through enhancement of collagenase and metalloproteinase activity. The study also substantiates that the combined effect of both alcohol and smoking will produce more destructive and deleterious effect on the periodontium and increases the mortality rate of the tooth.

Since, this study was of a cross sectional, noninterventional nature conducted on a modest sample of 150 subjects, studies with larger sample sizes need to be carried out in future to endorse the results observed in our study.

\section{REFERENCES}

1. Worman $\mathrm{HJ}$. A Icoholic liver disease. A vailable from: www.columbia.edu. (A ccessed: 9-06-2006).
2. Liu CM, Hou LT, W ong MY, Rossomando EF. Relationships between clinical parameters. Interl eukin-1 $\beta$ and histopathologic findings of gingival tissue in periodontitis patients. Cytokine 1996;8:161-67.

3. Dongari-Bagtzoglou $A L$, Ebersole JL. Increased presence of interleukin-6 (IL -6) and I L -8 secreting fibroblast subpopulations in adult periodontitis. J Periodontal 1998;69:899-910.

4. Mahajan BK. M ethods in biostatistics (6th ed). New Delhi: J aypee B rothers M edical Publishers 1999:130-56.

5. Christen A G. Dentistry and the alcoholic patient. Dent Clin N orth Am 1983;27:341.

6. Drake CW. Three-year tooth loss among black and white older adults in North Carolina. J Dent Res 1995;74:675-80.

7. Farley JR, Fitzsimmons R, Taylor AK, Jorch UM, Lau KH. Directs effects of ethanol on bone resorption and formation in vitro. A rch Biochem Biophys 1985;238:305-14.

8. O ettinger-Barak O, Barak S, M achtei EE, A rdekian L, Baruch $Y$, Peled M. Periodontal changes in liver cirrhosis and posttransplantation patients. I: Clinical Findings. J Periodontol 2001;72:1236-40.

9. O ettinger-Barak $O, M$ achtei EE, B arak S, B aruch $Y, A$ rdekian $L$, Peled M. Periodontal changes in liver cirrhosis and posttransplantation patients. II: Radiographic Findings: J Periodontol 2002;73:313-16.

10. M ovin S. R elationship betw een periodontal disease and cirrhosis of the liver in humens. J Clin Periodontol 1981;8:450-58.

11. Johnson GK, Hill M. Cigarette smoking and the periodontal patient. J Periodontol 2004;75:196-209.

\section{ABOUT THE AUTHORS}

\section{K Vijay Raghava (Corresponding Author)}

Reader, Department of Periodontics, Sri Rajiv Gandhi College of Dental Sciences, Cholanagar, Hebbal, RT Nagar, B engaluru-560032 Karnataka, India, e-mail: vijaykepu@yahoo.com

\section{H Shivananda}

Reader, Department of Periodontics, KVG Dental College, Sullia DK, Karnataka, India

\section{Darshan Mundinamane}

Reader, Department of Periodontics, RV Dental College, Bengaluru Karnataka, India

\section{Vinita Boloor}

Reader, Department of Periodontics, Y enepoya Dental College $M$ angalore, K arnataka, India

\section{Biju Thomas}

Professor and Head, Department of Periodontics, A B Shetty M emorial Institute of D ental Sciences, M angalore, K arnataka, India 